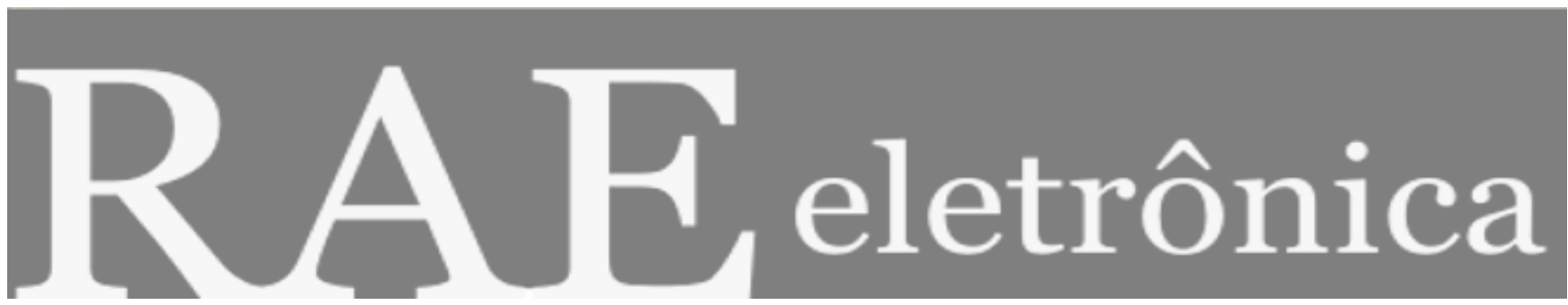

RETÓRICA ORGANIZACIONAL:

LÓGICA, EMOÇÃO E ÉTICA NO PROCESSO DE GESTÃO

Por:

Alvair Silveira Torres Junior

RAE-eletrônica, Volume 1, Número 2, jul-dez/2002.

http://www.rae.com.br/eletronica/index.cfm?FuseAction=Artigo \&ID $=1458 \&$ Secao $=P W C \&$ Volume $=1 \&$ Numero $=2 \& A n o=$ 2002

CCopyright, 2002, RAE-eletrônica. Todos os direitos, inclusive de tradução, são reservados. É permitido citar parte de artigos sem autorização prévia desde que seja identificada a fonte. A reprodução total de artigos é proibida. Os artigos só devem ser usados para uso pessoal e nãocomercial. Em caso de dúvidas, consulte a redação: redacao@rae.com.br.

A RAE-eletrônica é a revista on-line da FGV-EAESP, totalmente aberta e criada com o objetivo de agilizar a veiculação de trabalhos inéditos. Lançada em janeiro de 2002, com perfil acadêmico, é dedicada a professores, pesquisadores e estudantes. Para mais informações consulte o site www.rae.com.br/eletronica.

RAE-eletrônica

ISSN 1676-5648

(C2002 Editora: Fundação Getulio Vargas - Escola de Administração

de Empresas de São Paulo.

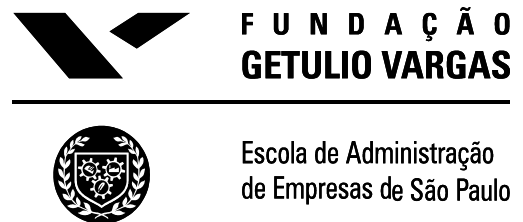




\title{
RETÓRICA ORGANIZACIONAL: LÓGICA, EMOÇÃO E ÉTICA NO PROCESSO DE GESTÃO
}

\author{
Alvair Silveira Torres Junior \\ Professor de Teorias da Administração e Adm. da Produção no UNIFAI- SP Mestre em Administração \\ de Empresas pela PUC-SP. Doutor em Comunicação Organizacional pela UMESP (Univ. Metodista) \\ E-mail: alvair@uol.com.br \\ Endereço: Rua Manoel Simões de Souza, 41 - São Bernardo do Campo - SP, 09689-050 \\ Interesses de pesquisa: mudança organizacional, gestão do conhecimento, comunicação \\ organizacional, modelos e novas estruturas organizacionais.
}

\section{RESUMO}

Dentro de um cenário no qual as organizações modernas têm adotado estratégias de mudanças organizacionais e inovações contínuas, visando o aumento da competitividade, propomos a aplicação de elementos retóricos na gestão das organizações, como forma de dar conta da nova realidade organizacional, necessariamente mais dependente da cooperação, colaboração e participação ativa de seus membros. A retórica organizacional visa instrumentalizar o gestor com um método de articulação das dimensões humanas básicas e os objetivos organizacionais. Ampliando a retórica aristotélica do verbal para o não-verbal, estabelece a prática de analisar e adotar ações administrativas que equilibrem e tragam significados éticos, emocionais e lógicos do emissor organizacional ao seu público interno, constituindo-se numa metáfora em que as ações passam a ser vistas como argumentos retóricos necessários para atingir o consenso, ou, o acordo plausível sobre o objetivo. Estudo de caso levado a cabo sob essa perspectiva demonstrou a viabilidade da análise retórica.

\begin{abstract}
We propose the application of rhetorical elements in management, as form to deal with the new organizational reality, necessarily more dependent of the cooperation, collaboration and participation of their members. The organizational rhetoric allows to the manager to get a method of articulation of human dimensions and organizational objectives. Enlarging the Aristotelian rhetoric from verbal to no-verbal, it established the practice of to analyze and to apply managerial actions with ethical, emotional and logical meanings to the internal public. It's a strategy of rhetorical arguments to reach the consensus, or, the plausible agreement on the organizational objective. One case study is discussed and it demonstrated the viability of the rhetorical analysis.
\end{abstract}

\section{PALAVRAS-CHAVES}

Retórica, gestão da mudança, comportamento organizacional, mudança organizacional, estudo de caso.

\section{KEY-WORDS}

Rhetoric, change management, organizational behavior, organizational change, case study. 


\section{INTRODUÇÃO}

O uso de metáforas na busca de novos caminhos para a gestão das organizações tem se constituído numa importante vertente do pensamento administrativo. Desde quando MORGAN (1986) publicou seu Images of Organization, pesquisadores e profissionais da gestão voltaram-se para a necessidade de usar imagens mentais, empréstimo de conceitos e intensificação da interdisciplinariedade, como formas de dar conta das novas questões e complexidades do nosso mundo contemporâneo.

Autores que trilham esse caminho, entretanto, devem estar conscientes das limitações de cada nova "viagem" que a metáfora possa vir possibilitar. Não é a simples coleção de novas imagens que poderão conceder ao gestor ferramentas adequadas ao exercício de suas atividades no interior das organizações. Sobretudo, a metáfora deve ser um apoio à exploração de fenômenos que de fato digam respeito à realidade organizacional, sua complexidade, seus fenômenos internos.

As organizações têm enfrentado um sem número de mudanças. A necessidade de lidar com novas situações a cada momento, as limitações de modelos matemáticos lineares rumo a modelos complexos, da lógica cartesiana à lógica fuzzy, o dissenso entre especialistas, os aspectos sócio-culturais e econômicos da globalização, tudo, em suma, sinaliza um fenômeno básico: a mudança contínua, ela mesma, uma imagem organizacional em si.

Aqui residem paradoxalmente o risco e a oportunidade na adoção das inovações organizacionais. Pensar a inovação como a simples necessidade de mudança, desvinculando-a de seu significado real como fenômeno, pode levar e tem levado às prescrições superficiais, ad-hoc, funcionais em certos casos e desastradas em outras. Porém, se atentarmos para a essência do fenômeno, isto é, o que ocorre na interação dos elementos do processo de mudança, descobriremos elementos normalmente velados, de difícil percepção e, quando vistos, considerados menores. Entretanto, são elementos que estão naturalmente presentes na vida organizacional, ligados ao processo de negociação e decisão em torno do que é lógico e aceitável para aquela organização.

As organizações que atendem ao chamado do mercado global lançam-se na busca de uma cultura de mudança, com o objetivo de transformar a inovação em rotina, porém, não se dão conta do esgotamento das verdades imperiosas nas respostas às perguntas: Que Fazer ? Como Fazer? Ressurge o campo das possibilidades, do plausível. Em lugar da verdade, a verossimilhança. Os processos decisórios e de gestão antes comparáveis ao cientificismo mais tradicional, dão lugar ao jogo de argumentos não só lógicos, mas também, emocionais, éticos, estéticos (CLEGG, HARDY E NORD, 1996). O fenômeno da argumentação antes restrito às interações do espaço social da empresa, tomam corpo, são extremamente necessários à cooperação no trabalho, na gestão das pessoas, mas permanece inexplorado. Nesse sentido, propomos o estudo e a instrumentalização desse fenômeno organizacional da mudança contínua, negociada, argumentada, persuadida, segundo uma imagem apropriada do campo social e da comunicação, ou seja, o resgate da retórica como elemento presente na vida organizacional e, portanto, capaz de ser alçado como ferramenta de gestão das organizações

Na parte II, que se segue, fazemos um resumo das abordagens mais recentes sobre o problema da gestão de mudança nas organizações e suas limitações em influenciar a efetiva adesão e participação dos membros da organização.

Na parte III, discutimos como a abordagem retórica pode dar conta da implantação de uma cultura de mudança nas empresas, sendo instrumento de gestão da participação e colaboração efetiva do coletivo de funcionários no processo contínuo de mudança.

$\mathrm{Na}$ parte IV, empreendemos um estudo de caso em um programa de mudança organizacional de sucesso, verificando como essa visão da retórica organizacional se constitui em fenômeno emergente, influenciador na condução do processo de gestão, mesmo sem estar instrumentalizado e conscientemente aplicado. Segue-se a conclusão. 


\section{A CULTURA DE MUDANÇA NAS ORGANIZAÇÕES}

Não há um consenso sobre as causas e até o sentido das mudanças que caracterizam o fenômeno da globalização, porém, mesmo para os céticos, aqueles que não acreditam ser a globalização proveniente de um processo histórico distinto, não há dúvidas de que as mudanças existem e contemplam amplos e variados aspectos da vida social.

Em especial, desde a década de 70, as organizações vêm incorporando mudanças nas suas bases técnica e social que alcançaram nos anos 90 um consenso tecnocrático (BOYETT, 1999). De forma geral elas apontam para a necessidade de engajar a força de trabalho em um novo padrão de comportamento organizacional, buscando a cooperação, participação e empreendedorismo compartilhado, sem uso do controle ou supervisão ostensivos.

De fato, mais até do que a mudança em uma direção específica ou na adoção de uma nova técnica, a mudança em si, estar preparado para ela, aceitá-la sem conflitos, com rapidez, agilidade, manipulá-la como algo natural sem o desgaste do poder, enfim, tudo que envolve fazer a mudança, tornando-a ação e prática social dentro da empresa, incorporando-a à cultura, constitui ponto central na gestão moderna e que pretendemos discutir nas suas relações com a imagem da retórica organizacional.

Um bom número de pesquisadores e consultores organizacionais têm tratado desse aspecto, recomendando que a empresa organize-se para a necessidade intrínseca da mudança (BOYETT, 1999) . Coletando os trabalhos da última década sobre o tema, em especial aqueles que são consenso na prática gerencial, seja nas revistas especializadas ou nos eventos empresariais, chegamos à classificação em dois grandes grupos que denominamos: escola dos processistas da mudança e escola do learning organization. Os dois grupos têm contribuído para a formação do saber organizacional voltado à necessidade da mudança, ou, como preferimos nomear, disseminam uma cultura de mudança.

O primeiro grupo "processistas da mudança" é representado por aqueles trabalhos que têm por objetivo orientar a implementação dos programas de inovação organizacional. Seus autores receberam forte influência da prática de fazer a mudança. Podemos citar os trabalhos da consultoria PRICE WATERHOUSE (1997) onde são enumerados 15 princípios básicos considerados pelos autores como diretrizes: enfrentar a realidade, agir sempre de acordo com a estratégia, exigir comando firme, estabelecer um clima de mudança, dar informações convincentes, fazer do cliente a mola-mestra da mudança, conhecer pessoas estratégicas, comunicar-se continuamente, reformular o sistema de medidas, utilizar todos os recursos, ser audacioso, aproveitar a diversidade de recursos, desenvolver novas capacidades na empresa, planejar e promover a integração de iniciativas.

Por sua vez, o ex-professor da Anderson School of Management in University of California, ICHAK ADIZES ( 1993), lista seis etapas para o processo de mudança: fazer o diagnóstico do problema; construir o empowerment, isto é, delegar poder e responsabilidade aos funcionários na solução dos pequenos problemas e aumentando a confiança mútua.; estudar a missão e os valores; realinhar a estrutura com a estratégia; reorganizar os sistemas de informação e reorganizar os sistemas de recompensa.

Como último exemplo dos representantes do grupo "processistas da mudança" temos o consultor e professor de Harvard, JOHN P. KOTTER ( 1997), que enumera 8 erros mais comuns nestes processos: não ter sentido de urgência, não envolver a alta direção e não formar uma equipe apoiada por ela para comandar a mudança, subestimar o poder da visão corporativa, não transmitir a visão de mudança, não fomentar o empowerment, não obter resultados em curto prazo, satisfazer-se logo com os resultados, deixando de consolidá-los para criar mais mudanças, não incorporar as mudanças à cultura da empresa. No segundo grupo, Learning Organization, encontramos uma maior uniformização das prescrições e um enfoque maior sobre a mudança do comportamento organizacional. Em síntese, seus seguidores prescrevem um modelo organizacional no qual as pessoas são estimuladas a aprimorar continuamente 
suas capacidades, de forma a trazer para a rotina o aperfeiçoamento constante das pessoas e da organização, traduzidos em melhor desempenho global e criação permanente do futuro.

Como um dos seus maiores expoentes e fundadores, PETER SENGE ( 1991) resume no que ele chama de cinco disciplinas a construção do modelo Learning Organization: primeira, domínio pessoal, isto é, aprender sobre seu trabalho e como expandir suas capacidades pessoais para fazê-lo melhor e alcançar as metas; a segunda, disciplina, modelos mentais, aprender a refletir sobre visões de mundo que orientem as decisões; a terceira, objetivos comuns, estimular o engajamento do grupo em relação à uma visão compartilhada de metas e valores do futuro; a quarta, aprendizado em grupo, de forma a ampliar visão para além dos limites pessoais; e quinta disciplina, desenvolver o pensamento sistêmico, fazendo a integração das outras quatro.

De forma geral, Peter Senge e os seguidores do Learning Organization, têm o mérito de ter disseminado através da expressão "aprender a aprender" a idéia da formação permanente como essencial para a empresa estar preparada para mudar continuamente, aproximando-se de uma perspectiva mais compatível com mudança cultural que a globalização passa a exigir das organizações.

Tais prescrições e recomendações dos mais consagrados consultores organizacionais transmitem o consenso do que deve ser feito, por outro lado, a maneira de se fazer é que tem esbarrado em pressupostos teóricos inconsistentes. Bastaria fazer o "engajamento das pessoas", ou a conscientização, como também se costuma dizer nas empresas. Uma visão que parte do pressuposto de que a ação social tem sua motivação no âmbito apenas racional, desconsiderando que esta é apenas uma de suas facetas ao lado de aspectos da interação social e seus simbolismos de emoção e moral social. Há toda uma interação cultural na qual o significado pessoal depende muito de como os argumentos são aceitos no interior da cultura ou contexto no qual se inserem (AKTOUF, 1996, p.p. 4048)

Propomos uma abordagem retórica que contemple todo o universo de significações lógicasemocionais-éticas no qual o indivíduo está inserido, seja da sua cultura ou da cultura organizacional, no interior das quais ele busca o sentido e decide suas ações, como sintetizou Motta ( MOTTA E CALDAS, 1998, p.27):

"Antes de mais nada, a cultura é linguagem, é código. Ela fornece um referencial que permite aos atores dar um sentido ao mundo em que vivem e as suas próprias ações. (....) Longe de fixar para cada um papéis dos quais não se pode escapar, a cultura influencia assim as orientações que tomam, no seio de cada conjunto social, os jogos estratégicos por meio dos quais cada indivíduo defende seus interesses e suas convicções."

\section{RETÓRICA ORGANIZACIONAL}

A perspectiva retórica é proposta a partir de quatro pontos básicos a fim de estabelecer sua aplicabilidade na organização. Primeiro, por trás do tecnicismo, dos procedimentos e dos mandamentos, identificamos a necessidade de transmitir uma mensagem básica: instaurar uma cultura da mudança e melhoria contínua na organização. Termos recorrentes como educação permanente, melhoria contínua, up-grade, atualização permanente, inovação constante, dentre outros, que sinalizam para o novo padrão de comportamento no trabalho.

Segundo, não basta só informar o conteúdo dessa mensagem básica. Há que se empreender um processo de persuasão. Terceiro, essa persuasão deve ser entendida no sentido retórico, isto é, pela própria natureza do novo comportamento exigido, participativo e cooperativo, o poder e controles ostensivos não mais funcionam ( KRAUSZ, 1991). Agora, os membros da organização devem ser convencidos e movidos pela argumentação retórica de cunho lógico, emocional e ético. Quarto, falar de retórica organizacional pressupõe que não haja privilégio só do discurso verbal, mas que a 
argumentação retórica esteja presente em símbolos, objetos, na cultura, nas falas, ações, na empresa como um todo, e não apenas no desempenho de um orador.

Essa possibilidade de empregarmos os princípios retóricos no cotidiano organizacional, de forma ampla, combinando discursos verbais e não-verbais, já se faz presente na obra de ARISTÓTELES (1985), na descrição que o filósofo faz das Artes Retórica e Poética, vistas nos personagens das tragédias gregas.

A argumentação da Retórica e o drama na Poética são considerados arte, na dupla acepção que este termo recebe dos gregos antigos. Arte, tradução do grego techné, designa uma técnica, habilidade espontânea ou adquirida através do ensino, como também, resultado de uma criação genial ou metódica. Retórica e Drama são arte porque combinam técnica e criação; a retórica, na invenção e organização dos argumentos; o drama na tragédia, como meio e maneira particular de imitação das ações da vida. Neste processo, não tratam do que é verdade, evidente, mas do que é plausível, verossimilhante.

Logo, se a arte imita a vida, porque não empregarmos uma das manifestações da arte para intervir na vida organizacional ? $\mathrm{Na}$ medida em que se faça uma análise integrada da obra aristotélica ( ARISTÓTELES, 1996, p.37-49 e 1985, p.p.211-213 ), percebe-se uma integração metodológica da Retórica com a Poética, da persuasão com a imitação de ações, do discurso com o drama, a ponto de falarmos de uma retórica nas ações, no drama da vida, ou como, em nosso caso, do drama nas organizações, de uma retórica organizacional.

Por outro lado, essa retórica ampliada, organizacional, que definimos como instrumento e campo próprios da arte de argumentar nos espaços de interação do cotidiano organizacional, não é, em nenhum sentido, sinônimo do que se costumou chamar de discurso vazio ou enganoso. Ao contrário, ela é o resgate de uma "gestão do discurso" por meio de argumentos escolhidos dentro de uma tríade do convencimento: lógica, emoção e ética, levando tais elementos a serem parte integrante das análises e práticas da gestão, através da sua efetivação equilibrada em atos, ações e práticas administrativas, ilustrados no estudo de caso.

São tais relações que ligam o drama da vida com a argumentação, a verificação de processos de convencimento e decisão com base na retórica, que conduziram-nos à pesquisa no estudo de caso e à possibilidade de analisarmos com elementos retóricos o processo de mudança organizacional. Primeiro, na existência de argumentos lógicos, emocionais e éticos dentro das decisões de implementação das mudanças organizacionais. Segundo, que tais implementações retóricas se manifestem de forma ampla, sejam em ações, falas, comportamentos e símbolos, constituindo um discurso retórico simbólico, verbal e não-verbal na organização.

Para nortear a pesquisa elegemos os elementos básicos da retórica aristotélica ( REBOUL, 1998) aplicáveis tanto ao discurso em si, quanto à representação do discurso e, portanto, aplicáveis ao verbal e não verbal. Em primeiro lugar identificamos a estrutura retórica dividindo-a em quatro elementos:

1) Gênero do discurso, que adaptamos como a essência da mensagem, a intenção organizacional, seu ato e propósito de fazer a mudança em dada direção.

2) Orador, ampliado para a noção de emissor da mensagem.

3) Audiência do discurso, que reconhecemos na figura da platéia ou da recepção, isto é, os funcionários da organização.

4) Meios de Prova, que adaptamos na retórica organizacional como sendo as ações de mudança, a estética, os fatos criados, todos servindo de exemplos à platéia.

Por sua vez, tais elementos foram cruzados com o tipo de argumentação que eles trazem para o discurso, sabendo-se que na retórica temos três tipos básicos que fazem-na aproximar-se do cotidiano, da vida real, do processo decisório que não busca a verdade, mas, sim, do que é plausível. Tratam-se das dimensões lógica, emocional e ética do discurso, o logos, pathos e ethos. 


\section{ESTUDO DE CASO}

No estudo de caso empreendemos uma pesquisa qualitativa através do método de caso simples (YIN, 1988), em uma montadora do ABC paulista, Empresa X, atualmente com cerca de 9.000 funcionários, focando o período de mudanças organizacionais pelo qual suas áreas operacionais passaram no intervalo dos anos 1990-1999.

\section{Mensagem: mudar ou morrer - o ato e propósito}

De início, nossa abordagem aponta para os primeiros anos nos quais a mudança foi discutida no seu conceito, direção e sentido a serem seguidos, ou seja, a mensagem contida no seu ato e propósito.

Os documentos, registros, personagens e nossas observações da época, anos de 92 e 93, apontam para o fato de que desde o primeiro momento a direção da empresa vinculou clara e abertamente o ato de mudar ao propósito de sobrevivência da organização, necessitando da colaboração e adesão efetiva dos funcionários às novas formas de trabalho, no sentido de permanecer líder e competitiva na nova realidade do mercado que surgia. Esse vínculo, por sua vez, realizou-se respeitando as três dimensões da argumentação: a lógica, a emocional e a ética.

Os argumentos lógicos encontram-se na constante divulgação dos números e fatos que demonstram o avanço da concorrência, as dificuldades dos mercados interno e externo, a competição internacional, e, mais palpável ao conjunto dos trabalhadores, a queda nas vendas e o produto mais caro em relação aos outros competidores.

O emocional, por sua vez, vai da fronteira com o lógico, a sobrevivência, para tocar naquilo que é a identificação do trabalhador com a organização: a continuidade da sua história de vida na empresa, haja vista que a média de tempo de casa encontrava-se na faixa de 6 a 10 anos em 93, o que representava mais de $60 \%$ das pessoas com tempo igual ou superior a 6 anos. Esse apelo, por outro lado, recebeu um forte reforço por conta da crise econômica de 92 , quando houve o primeiro prejuízo da empresa no Brasil.

Se, do lado do aspecto emocional, a mensagem de uma Nova Fábrica para 2000 era relacionada à solução dos problemas de perda de mercado, competitividade e redução de pessoal, o aspecto ético estava presente por meio da discussão e negociação dessa solução com a Representação de Empregados, a conhecida Comissão de Fábrica, ligada ao Sindicato dos Metalúrgicos do ABC da CUT. A constituição do ato e seu propósito, nesse sentido, foi o primeiro passo. Estabelecer a mensagem fundamental de todo texto retórico e dramático que será construído, delineando seus aspectos lógicos, emocionais e éticos, relacionando-os com valores do ser humano em geral, sem serem específicos daquela platéia, mas, ao contrário, amplos e gerais, como foram-no a busca da competitividade, a sobrevivência da organização com seus membros e o respeito ético, incluindo aí os contestadores. Tais princípios são as premissas maiores a serem trabalhadas, considerando, depois, aquilo que possa haver de específico em determinado público, através dos outros elementos (CHENEY, 1991).

\section{O EMISSOR: A REDE DE GESTORES}

Nessa etapa todo e qualquer chefe foi preparado para a mudança, ensaiado, inventado em suas ações, constituindo uma rede de gestores. Por outro lado, houve uma etapa retórica de invenção dos aspectos lógicos, emocionais e éticos das ações da chefia, que depois, passaram a ser argumentos perante a platéia. O primeiro aspecto, o lógico, foi visto na necessidade de competitividade que emergiu nos chefes pelo lado da tradição em qualidade e liderança postas em confronto com o benchmarking de outras empresas, os exemplos do mercado, inclusive da concorrência, as visitas e reuniões versando sobre esses aspectos e que passaram a ser referência em suas relações com a platéia. 
O emocional foi visto naquilo que as dúvidas sobre a sobrevivência da organização, seu futuro, atingiram o orgulho fortemente presente entre os chefes em relação à Empresa $X$ e à posição que nela ocupam. E, finalmente, o ético visto no sentimento de lealdade cultivado entre a instituição e os chefes, e na oportunidade que lhes foi concedida para reciclagem e adaptação às mudanças. Ambos estão imbricados numa forte identidade da chefia com a empresa, construída e presente numa relação estável. Nesse sentido, contrastando com a hipótese corrente de substituição dos chefes e líderes por pessoas mais jovens ( BERGAMINI, 1994), os cargos de chefia na Empresa X, aqui considerados a partir do seu primeiro nível, mestres de produção, até o presidente e diretoria, eram ocupados em dezembro de 98 por pessoas com idade média de 45,9 anos e tempo de casa médio de 20,4 anos. Apesar desse levantamento obtido no departamento de RH da empresa, enfocando a chefia, não ter sido possível realizar em outros anos, o que impossibilitou a comparação, não há dúvida de que tais números desencorajam uma relação direta entre mudanças comportamentais e substituição de chefes por outros mais jovens.

\section{A RECEPÇÃO: O ORGULHO DA PLATÉIA}

A platéia surge como elemento sobre o qual queremos que nossos argumentos retóricos surtam efeito através do alcance do comportamento esperado. Há aqui duas etapas distintas nesse papel que a audiência exerceu no processo retórico da mudança organizacional

Num primeiro momento a platéia assiste ao elenco desempenhar as cenas, aquelas ações simbólicas que retoricamente passam a impressionar suas mentes e a interagir de forma ainda passiva, reflexiva e condicionada pelos gestores, para, em seguida, no segundo momento, sua audiência transformar-se em parte do espetáculo, não como conclusão ou fim do processo, mas como meio de persuasão. A partir disso a interação passa a ser ativa por meio de cenas próprias da platéia. Ações que também surgem como símbolos de força retórica.

No que diz respeito ao pathos, identificamos cenas em que os funcionários se vêem com seus amigos, parentes, filhos, familiares em geral, ligando a empresa com os dramas naturais da vida cotidiana. Por iniciativa dos gestores, a empresa passa a realizar uma série de eventos que fizeram essa aproximação. Palestras direcionadas às famílias, em especial às esposas e companheiras, enfocando aspectos de saúde, educação, economia no lar.

Aqui também, nessa dimensão emocional da invenção da platéia, o aproveitamento da marcante identidade dos funcionários com a instituição é um aspecto central do discurso não-verbal. Por exemplo, dados colhidos em pesquisa de clima organizacional realizada pela empresa entre outubro de 98 e setembro de 99, demonstram , apesar do aparente paradoxo no descontentamento detectado dos funcionários na sua relação com a chefia, que a identidade dos funcionários e sua dimensão emocional se projetam e repousam sobre a figura da empresa. Vejamos os dados obtidos em algumas perguntas:

Você aconselharia um amigo a trabalhar na Empresa X?

- $\quad 93 \%$ aconselhariam.

Você se sente satisfeito trabalhando na Empresa X, considerando tudo o que ela lhe oferece ? - 94\% satisfeitos.

Você se sente motivado em aumentar a produtividade do seu setor?

- $80 \%$ estão motivados .

Ou, ainda, nas notas dos itens que avaliam a mobilização pró-empresa:

$\mathrm{O}$ futuro da Empresa $\mathrm{X}$ deve ser preocupação de todos ?

- $\quad$ pessoal de chefia -10

- pessoal operacional - 9,8

Você procura alcançar resultados melhores do que aqueles que a empresa espera do seu trabalho ? -pessoal de chefia - 9,2 
-pessoal operacional - 9,2

De forma geral, há uma forte identidade dos funcionários e dos gestores com relação à empresa. No caso da Empresa X a personificação da organização constitui-se no emissor principal do discurso, aquele que deve ter sua credibilidade preservada em relação à platéia.

O ethos, por sua vez, foi constatado na maturidade do relacionamento entre empresa e seus empregados e representantes. Na ética do respeito da empresa aos contestadores da mudança, em especial, aos representantes da Comissão de Fábrica e Sindicato, visto na busca de negociação, solução de conflitos e disputas, sempre com base em ações éticas de conduta séria dos argumentos.

\section{OS MEIOS DE PROVA: ESTÉTICA E EXEMPLOS}

Na Empresa X muitas inovações técnico-administrativas foram e vêm sendo aplicadas, mas é o Kaizen que sem dúvida veio servir de meio de prova ao processo de mudança. Foi aplicado não só como técnica de melhoria contínua dos indicadores operacionais e eliminação de desperdícios, mas como exemplo de prova para a mudança organizacional.

Na sua aplicação na Empresa X, além dos aspectos da invenção que seguiram orientações idênticas aos outros símbolos do drama, isto é, a lógica de evitar desperdícios, a emoção da participação em grupo e a ética de ouvir os operários, queremos destacar a função do Kaizen como elemento de prova, através de suas aplicações na fábrica não só como técnica, mas como exemplo da "boa mudança", revestindose de todo um aparato estético e simbólico.

Máquinas foram pintadas em cores diversas e nada ortodoxas, plantas foram distribuídas pela platéia, pisos foram pintados e mantidos limpos e brilhando. Talentos da platéia tiveram espaço para pintar murais, fazer trabalhos desinteressados, direcionados para uma expressão estética de embelezamento da área de trabalho. A platéia junto com os gestores também construiu o cenário a medida que os Kaizens foram sendo realizados. Algo inédito e não previsto pelos tecnicistas japoneses do toyotismo.

O piso da fábrica, além de limpo, passa a ser pintado e decorado. Em alguns locais, nas montagens por exemplo, aplicam-se resina no piso tornando-o liso e brilhante, com ausência de óleos, graxas, riscos ou resíduos impregnados. Muitas das casas de operários certamente não dispõem de um piso daqueles. $\mathrm{Na}$ linha de montagem são instalados luminosos que identificam os postos, bem como, colunas giratórias com gráficos e orientações ilustradas.

Por toda fábrica vasos com plantas passam a fazer parte da paisagem fabril. Áreas reservadas para descanso são decoradas com mesas e bancos impecáveis. Operários com aptidão para pintura, serralheria ou marcenaria são incentivados a construir não só artefatos que sejam funcionais, mas que também sejam bonitos, ou, até mesmo, objetos que são mais para decorar do que para outra finalidade.

De forma geral, além dos preceitos de ordem e limpeza que acompanham os conceitos do toyotismo e do lean management, na Empresa $\mathrm{X}$ as mudanças devem ter um visual diferenciado em direção ao esteticamente bonito e colorido. Aos olhos de um analista convencional tal prática seria uma contradição diante do dispêndio de tempo, recursos e custos maiores exigidos para a manutenção dessa forma retórica de gestão da técnica, porém, é uma forma da platéia engajar-se no novo, senti-lo agradável, dele participar nem que seja na decoração. Tornar-se parte e protagonista do que está sendo mudado com esse novo cenário.

\section{CONCLUSÃO}

Como conclusão geral, a análise revelou a presença de elementos retóricos na gestão da mudança organizacional, formando um discurso persuasivo verbal e não-verbal, que influenciou decisivamente no processo de gestão e na decisão dos membros da organização no sentido da sua colaboração e forma de participação. 
Salvo algumas especificidades do caso analisado, com relação à identidade, história e tradição daquela empresa, o que sobressai como ferramenta básica de gestão é a viabilidade de planejar e conceber ações administrativas, alinhadas e equilibradas segundo significados lógicos, emocionais e éticos para o público interno.

Nesse sentido, através do conceito retórico surge a possibilidade de alinhar e articular diversas manifestações da ciência administrativa em busca de um modelo gestor que contemple toda a complexidade do humano, central para tornar a empresa integrada, inteligente, flexível, dentre outras qualificações exigidas pela competitividade e apontadas na literatura especializada. Inteligência emocional, responsabilidade social, ética no trabalho, busca da rede de líderes, dentre outros temas humanísticos, surgem como sintomas interpretados e geridos mais eficazmente dentro de um quadro de retórica organizacional.

Primeiro, a lógica, presença tradicional e preponderante na ciência administrativa desde Taylor, integra e direciona, sem esforço, a esfera global das atividades econômicas do ser humano. Entretanto, a recente necessidade competitiva de integrar os membros da organização na cooperação e participação efetivas, trazem o emocional e o ético como segundo e terceiro fatores.

Conceitos de inteligência emocional, valores da organização, gestão do ser-humano, ou, até mesmo as mais recentes descobertas da neurociência em que as emoções são a base do raciocínio lógico, encontram na imagem retórica uma aplicação mais direta na organização. Com a retórica organizacional aqueles e outros elementos de gestão dos recursos humanos passam a ser subsídios para criar efetivos argumentos emocionais em termos de atos, ou, ainda, na análise dos significados ou repercussões emocionais das tomadas de decisão. Uma demissão, por exemplo, ganha outras possibilidades se além de ser vista pela lógica, for considerado seu impacto emocional na organização. Pórem, desde que a teoria dos jogos trouxe para o estudo das decisões a questão dos resultados de soma diferente de zero, isto é, em certas condições a cooperação dos competidores maximiza os resultados, uma demissão, ainda no mesmo exemplo e dependendo de como é feita, além do emocional pode representar um significado de cunho ético decisivo para trazer ou não a cooperação ao trabalho e maximizar os ganhos para as partes.

Pensar retoricamente a organização significa, portanto, pensar contribuições e consequências lógicas, emocionais e éticas na gestão.

\section{Artigo recebido em 10.06.2001. Aprovado em 10.06.2002}

\section{REFERÊNCIAS BIBLIOGRÁFICAS}

ADIZES, Ichak. Gerenciando as mudanças - o poder da confiança e do respeito mútuos. São Paulo, Pioneira, 1993.

AKTOUF, Omar. Os simbolismos e a Cultura da Empresa: limitações conceituais e lições empíricas.in

ARISTÓTELES. Arte retórica, arte poética. Rio de Janeiro, Ediouro, 1985.

. Poética in Aristóteles, Coleção os Pensadores. São Paulo, Nova Cultural, 1996.

BERGAMINI, Cecília Whitaker. Liderança - Administração do Sentido. São Paulo, Atlas, 1994. 


\section{PRÊMIO PWC INOVAÇÃO EM GESTÃO - RETÓRICA ORGANIZACIONAL: LÓGICA, EMOÇÃO E \\ ÉTICA NO PROCESSO DE GESTÃO \\ Alvair Silveira Torres Junior}

BOYETT, Joseph e Jimmie. O Guia dos Gurus - os melhores conceitos e práticas de Negócios. Rio de Janeiro, Campus, 1999

CHANLAT, Jean-François. O indivíduo na Organização; dimensões esquecidas, v. II São Paulo, Atlas, 1996, pp. 39-78.

CHENEY, George. Rhetoric in an Organizational Society - managing multiple identities. Columbia, South Carolina, University of South Carolina Press, 1991.

CLEGG, Stewart R., HARDY, Cynthia, NORD, Walter R. Handbook of Organization Studies. London, Sage, 1996.

KOTTER, John P. Liderando Mudança - um plano de ação para fazer as coisas acontecerem. Rio de Janeiro, Campus, 1997.

KRAUSZ, Rosa. Compartilhando o poder nas organizações. São Paulo, Nobel, 1991.

MORGAN, Gareth Images of Organization. Thousand Oaks, California, Sage Publications, 1986.

MOTTA, Fernando C.P. Cultura e Organizações no Brasil in MOTTA e CALDAS. Cultura Organizacional e Cultura Brasileira. São Paulo, Atlas, 1998.

REBOUL, Olivier. Introdução à retórica. São Paulo, Martins Fontes, 1998.

SENGE, Peter M. A Quinta Disciplina - arte, teoria e prática da organização de aprendizagem. São Paulo, Ed. Best Seller, 1991.

WATERHOUSE, Price. Mudando para melhor - as melhores práticas para transformar sua empresa. São Paulo, Atlas, 1997.

YIN, Robert K. Case Study Research - Design and Methods. California, Sage Publications, 1988. 